\title{
SNX3, UBE20 and SNX27 Protein Expressions are Altered in the Hypothalamus of High-Fat Diet Fed Mice. Possible Implications for Retrograde Protein Trafficking
}

Leonardo Rossi de Oliveira ${ }^{1}$, Nathália Augusta de Oliveira Gomes ${ }^{1}$, Luana Assis Ferreira ${ }^{1}$ Mariana Lacerda de Freitas ${ }^{1}$, Aryane Mayra Fernandes ${ }^{1}$, Celio Jose de Castro Junior ${ }^{1}$, Fernanda S Jehee ${ }^{1}$, Adriana Aparecida Bosco ${ }^{1}$, Karla Simone Fernandes ${ }^{1 *}$

${ }^{1}$ Instituto de Ensino e Pesquisa, Hospital Santa Casa de Misericórdia de Belo Horizonte (IEP-SCBH), P.O. Box: 30250-140, Belo Horizonte, Brazil.

fernandeskss@yahoo.com.br

*Corresponding Author: Karla Simone Fernandes, Instituto de Ensino e Pesquisa, Hospital Santa Casa de Misericórdia de Belo Horizonte (IEP-SCBH), P.O. Box: 30250-140, Belo Horizonte, Brazil.

Abstract

Obesity is a worldwide health problem characterized by overeating and satiety regulation breakdown. Arcuate nucleus (ARC) in the hypothalamus and controls energy homeostasis mainly through leptin binding to its receptors (ObR). Defective central response to leptin in obesity also involves impairment of endosomal ObR recycling, degradation, and trafficking, which compromises receptor steady state in the plasma membrane. Here we report that ARC from high-fat diet (HFD) mice presented alterations in the expression of proteins involved in endosomal retrograde transport. Indeed, we observed a significant decrease of SNX3 and UBE2O levels as analyzed by confocal microscopy, suggesting an impairment of the endosomal retrograde routein the ARC of HFD fed mice when compared to controls. On the other hand, the fast recycling protein marker, the SNX27, was upregulated in the ARC of HFD fed mice, suggesting that some kind of compensation is happening.

\section{INTRODUCTION}

Arcuate nucleus (ARC) in hypothalamus transduce orexigenic and anorexigenic signals generated by hormones, like leptin, ghrelin, and insulin, triggering food intake/energy expenditure ratio regulation (SCHWARTZ, 1997; ELIAS, 1999; COWLEY, 2001; BOURET, 2012; BAVER, 2014). Leptin bind to ObR (leptin receptor), activating neurons signals that contribute to satiety, being considered an antiobesity hormone (COLL, 2007; ZHANG, 1994). Overconsumption of dietary fats has been described as inflammatory affecting leptin responsiveness of ARC neurons (TRAN, 2016). The resistance or cell hyporesponsiveness to leptin is involved in satiety ablation and obesity in mice (MÜNZBERG, 2004). There are some hypotheses proposed for leptin resistance (BALLAND, 2015; CUI, 2017), among them we are interested in investigating the ObR recycling machinery proteins expression in the hypothalamus of obese mice, which may be related to leptin resistance. We described earlier that transcripts of important endosomal recycling genes are altered in the ARC of HFD fed mice (RUBATINO, 2018).

Endosomal transport is essential for the plasma membrane receptors homeostasis (SCOTT, 2014; BELOUZARD, 2004). ObR requires internalization after the binding of leptin (FRÜBECK, 2006), and then sorted to one of three destinations: the degradation, recycling via Trans-Golgi-Network (TGN) or via the plasma membrane (SEAMAN, 2008). Retromer complex is a protein trimmer essential for sorting of cargo protein (SEAMAN, 1997; SEAMAN, 1998). Actin filaments nucleation is essential for endosomal transport and involves the Arp2/3 complex. (HAO, 2013). WASH complex is a nucleating promoting factor (NPF) and binds to Arp2/3, promoting actin nucleation (DERIVERY, 2009; DULEH, 2010; SEAMAN, 2013), thus allowing the endosomal trafficking. WASH 
SNX3, UBE20 and SNX27 Protein Expressions are Altered in the Hypothalamus of High-Fat Diet Fed Mice. Possible Implications for Retrograde Protein Trafficking

ubiquitylation is only possible through E3 TRIM27 binding to retromer's subunit VPS35, which is only possible through MAGEL2 intervention (SEAMAN, 2013; GAUTREAU, 2014). To MAGEL2-TRIM27 interaction to happen, the E2 UBE2O is essential for the whole process (HAO, 2013).

The sorting nexin 3 (SNX3) is a member of SNXPX nexin subfamily able to target retromer to early endosomes via PI3P domain, and also is required for late-endosome Golgi recycling of some cargo proteins (GALLON, 2015). SNX27 has been described as containing amino acid motifs that contribute to retromer-mediated transport of fast recycling receptors, as $\beta 2$ (LAUFFER, 2010) and $\beta 1$ (TEMKIN, 2011) adrenergic receptors, from early endosomes to the plasma membrane. There are other proteins and complexes that participate in intracellular trafficking, but they are out of the scope of this communication. For more information upon them, we suggest read Gallon (2015). On the other hand, non-recycled cargos are directed to lysosomal degradation pathways.

Our group has previously described that high-fat diet (HFD) fed C57BL/6J mice presented decreased transcript levels for Ube2o, Igfr2, Cdm6pr, and Tbc1d5 genes, and showed significant body weight gainand hyperglycemia (RUBATINO, 2018). In this short communication, we evaluate the protein expression of SNX3, SNX27, and UBE20 using immunofluorescence in the ARC of these animals.

\section{Material AND Methods}

\section{Animal Model of Diet-Induced Obesity}

All animal procedures were approved by the ethics committee at IEP-SCBH, 0001-15. The high-fat-dietinduced obesity murine experimental model was already described in Rubatino (2018). Thus during that period, StD $(3.7 \mathrm{kcal} / \mathrm{g}, 10 \%$ from saturated fat) and HFD (5.3 kcal/g, 60\% from saturated fat), were purchased from PragSoluçõesBiociências, Brazil. Male,

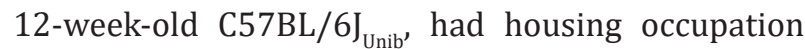
up to four animals per cage. Temperature $\left(22 \pm 2^{\circ} \mathrm{C}\right)$ and light cycle (12-h light/dark) were controlled and animals had food and water ad libitum. Mice were randomized into two groups of six animals: one was fed for 8 weeks with HFD and the other group received the StD for 8 weeks. HFD-fed mice were significantly heavier $(42.3 \pm 4.3 \mathrm{~g} ; 45,8 \%)$ than mice that received the StD $(29 \pm 1.9 \mathrm{~g} ; \mathrm{p}<0.001)$. They also presented significant hyperglycemia $(192.3 \pm 27.3 \mathrm{mg} /$ $\mathrm{dL})$, when compared with StD mice $(45.4 \pm 14.4 \mathrm{mg} /$ $\mathrm{dL} ; \mathrm{p}<0.001$ ). The plasma leptin levels of HFD-fed mice were significantly increased $(182 \pm 62 \mathrm{ng} / \mathrm{mL})$ when compared to StD-fed mice $(81.9 \pm 62.2 \mathrm{ng} / \mathrm{mL})$. All data were derived from one representative assay of three independent ones (RUBATINO, 2018). Now, we are evaluating SNX3, SNX27 and UBE2O protein expression in ARC of these animals.

\section{Intracardiac Perfusion}

At 20 weeks of life, animals were submitted to intracardiac perfusion to have their brains removed. They were anesthetized with ketamine and xylazine at a dose of $150 \mathrm{mg} / \mathrm{kg}$ and $10 \mathrm{mg} / \mathrm{kg}$, respectively. Using an infusion pump, we injected $20 \mathrm{~mL}$ of PBS (pH=7.4), followed immediately by $20 \mathrm{~mL}$ of paraformaldehyde solution $(4 \%, \mathrm{v} / \mathrm{v}, \mathrm{pH}=7.4)$. After the process, their brains were removed, stored in paraformaldehyde solution for $24 \mathrm{~h}$, and then stored in PBS at $4^{\circ} \mathrm{C}$.

\section{Immunofluorescence Staining}

The brains stored in PBS had their hemisphere divided and then coated in agarose. Coronal sections were collected using the Vibratome, Leica, VT1000 $\mathrm{S}$. We used the Paxinos atlas in order to guide the cutting process of the hypothalamic ARC region. Immunostaining of SNX3, SNX27, and UBE20 proteins were performed in 5 brain sections per group $(50 \mu \mathrm{m}$ thick). Control groups for each experiment were made with only secondary antibody immunostaing in order to eliminate any unspecific biding during the analysis. Brain sections were blocked for $30 \mathrm{~min}$ at room temperature with $3 \%$ BSA (Sigma-Aldrich) and 0,1\% Triton X-100 (Sigma-Aldrich). Then, the sections were incubated overnight or during $72 \mathrm{~h}$, depending on the primary antibody, at $4{ }^{\circ} \mathrm{C}$. The primary antibodies (all diluted in 3 \% BSA) used were Anti-SNX27 (SantaCruz Biotechnology; CAT\# sc-366387) raised in rabbit, Anti-SNX3 (Abcam; CAT\# ab56078) raised in mouse and Anti-UBE2O (SantaCruz Biotechnology; CAT\# sc109125) raised in goat. Sections were washed three times with PBS and incubated with the secondary antibody for $3 \mathrm{~h}$ at room temperature. The secondary antibodies used were AlexaFluor 488 anti-mouse IgG (Thermo Fisher Scientific; CAT\# A11029), antigoat IgG (Thermo Fisher Scientific; CAT\# A11055) and anti-rabbit IgG (Thermo Fisher Scientific; CAT\# A21206). After the incubation with the secondary 
SNX3, UBE20 and SNX27 Protein Expressions are Altered in the Hypothalamus of High-Fat Diet Fed Mice. Possible Implications for Retrograde Protein Trafficking

antibody, the sections were washed 3-4 times with PBS and mounted using Fluoromount Aqueous Mounting Medium (Sigma-Aldrich; CAT\# F4680). Then, samples were stored at 2-8 ${ }^{\circ} \mathrm{C}$ in a dark box for later analysis.

\section{Confocall Analysis}

Images of the ARC stained for SNX3, SNX27 and UBE2O were acquired using a 20x objective. For this analysis, we used the CarlZeiss 5 Live confocal located at Center of Acquisition and Processing of Images (CAPI) - ICB - UFMG. Before every analysis, we set the equipment (parameters not shown) using the control sample with only the secondary antibody, in order to eliminate any unspecific staining. This sample had fluorescent units equal to 1 , and then we performed the rest of the experiment. Z-stack was set at 20 sections of 2 , $5 \mu \mathrm{m}$ each and the mean fluorescence intensity was considered for comparison between groups.

\section{Statistical Analysis}

All data are presented as table and graphs as mean and standard deviation, and the confidence interval considered was 95\%. Kolmogorov-Smirnov test was applied to select the distribution profile of continuous data, assuming the parametric distribution. The in situ expression data were analyzed using the Student's t-test. Software R 3.4.2 and GraphPadPrisma 5.0 were used for the statistical analysis and graph plotting.

\section{RESULTS}

\section{HFD Fed Mice Present Diminished Levels of SNX3 Protein Expression in the ARC.}

We have earlier described that HFD-fed C57BL/6J $\mathrm{Unib}_{\text {}}$ miceacquire obese phenotype, among other alterations (RUBATINO, 2018). Indeed, HFD administration is a very used method of inducing obesity (KLEINERT, 2018). Now, hypothalamic samples of these HFD and StD mice were evaluated for protein expression levels by confocal microscopy immunostaing analysis. The SNX3 is an adapter sorting protein of SNX-PX subfamily essential to retromer complex recruitment and WASH complex activation, contributing to TGN retrograde transport. It was observed that ARC of HFD-fed mice presented a smooth decrease $(14,80$ $\pm 0,55 \mathrm{AU})$ in SNX3 expression when compared to ARC from StD-fed mice (16,37 $\pm 0,39$ AU) ( $p=0,0494)$ (Figure 1; Table1).

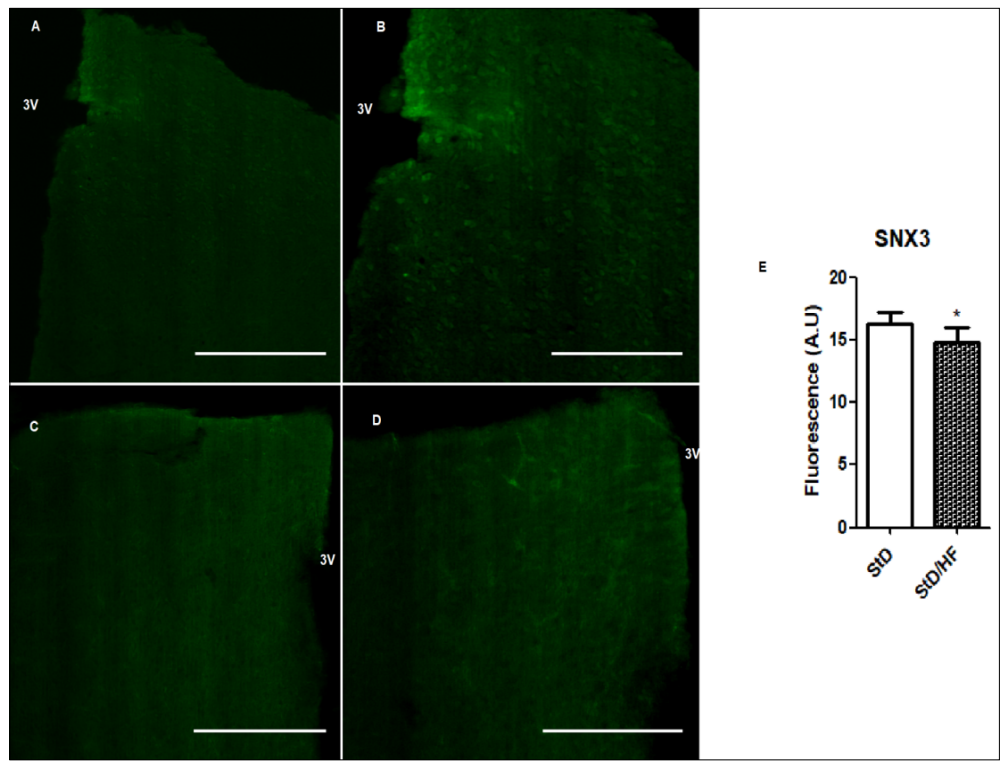

Figure 1. Mice fed with HFD from the $12^{\text {th }}$ week of life until the $20^{\text {th }}$ week of life (HFD) showed a decreased SNX3 protein expression in the ARC when compared to controls (StD). A and B show representative images of SNX3 immunostaining in ARC from StD mice using 10x and 20x objective, respectively. C and D show representative images of SNX3 immunostaining in ARC of HFD mice using 10x and 20x objective, respectively. E: Confocal quantification analysis showing a significant reduction in SNX3 immunofluorescence signal in the ARC from HFD mice (14,80 \pm 0,55 AU) when compared to StD (16,37 \pm 0,39 AU) group. ( $p=0,0494 ; 3 \mathrm{~V}=$ third ventricle; AU= arbitrary unit; Scale bar: $A-C=500 \mu \mathrm{m} ; B-D=100 \mu \mathrm{m})$. Data are represented as mean \pm standard deviation of arbitrary units (AU) of fluorescence. Statistical significance was calculated Kolmogorov-Smirnov test, followed by Student's T test. 
SNX3, UBE20 and SNX27 Protein Expressions are Altered in the Hypothalamus of High-Fat Diet Fed Mice. Possible Implications for Retrograde Protein Trafficking

\begin{tabular}{|c|c|}
\hline $\begin{array}{l}\text { HFD Fed Mice Present Diminished Levels of } \\
\text { E2-Conjugase UBE20 Protein Expression in } \\
\text { the ARC }\end{array}$ & $\begin{array}{l}\text { polyubiquitination of WASH complex and formation of } \\
\text { actin filaments to endosome transport (HAO, 2013). It } \\
\text { was observed that in situ expression of UBE2O in ARC } \\
\text { is hugely decreased in HFD-fed mice }(17,11 \pm 0,51 \mathrm{AU})\end{array}$ \\
\hline $\begin{array}{l}\text { Little is known about UBE2O functions, but it has been } \\
\text { described that UBE2O E2-conjugase is essential for }\end{array}$ & $\begin{array}{l}\text { when compared to the StD animals }(32,23 \pm 1,31 \mathrm{AU}) \\
(\mathrm{p}<0,0001) \text { (Figure 2; Table } 1) .\end{array}$ \\
\hline
\end{tabular}

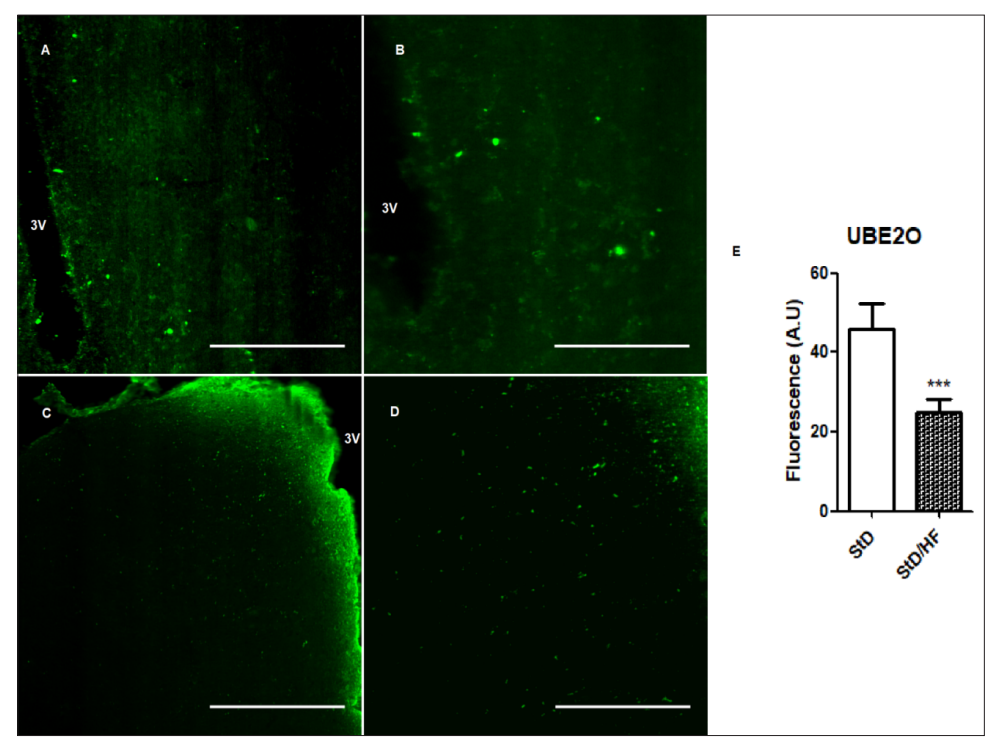

Figure 2. Mice fed with HFD from the $12^{\text {th }}$ week of life until the $20^{\text {th }}$ week of life (HFD) showed a decreased E2conjugase UBE2O protein expression in the ARC when compared to controls. A and B show representative images of UBE2O immunostaining of StD group using 10x and 20x objective, respectively. C and D show representative images of UBE2O immunostaining of HFD mice using $10 x$ and $20 \times$ objective, respectively. E: Confocal quantification analysis showing a huge reduction in UBE2O immunofluorescence signal in the ARC from HFD mice $(17,11 \pm 0,51$ $A U)$ when compared to StD mice $(32,23 \pm 1,31 \mathrm{AU}) .(p<0,0001 ; 3 \mathrm{~V}=$ third ventricle; $A U=$ arbitrary unit; Scale bar: $A-C=500 \mu \mathrm{m} ; B-D=100 \mu \mathrm{m})$. Data are represented as the mean \pm standard deviation of arbitrary units (AU) of fluorescence. Statistical significance was calculated Kolmogorov-Smirnov test, followed by Student's T test.

HFD Fed Mice Present Increased levels of SNX27protein Expression in the ARC

Detection of decreased levels of SNX3 and UBE2O protein expression suggested a possible impairment in TGN retrograde transportin the ARC of HFD-fed mice. Therefore, we decided to evaluate the in situ expression of SNX27 protein in the ARC of these animals. It has been described that SNX27 is involved in the fast recycling of receptors to the plasma membrane. We have found that HFD mice presented increased levels of SNX27 expression $(15,52 \pm 0,93$ $\mathrm{AU})$ in the ARC when compared to the StD group $(12,07 \pm 1,00 \mathrm{AU})(\mathrm{p}=0,0367$, (Figure 3, table 1)

The data were summarized in Table 1, thus UBE20 expression in ARC is hugely reduced in HFD fed mice when compared to lean mice. The SNX3 expression in
ARC was also significantly decreased $(\mathrm{P}=0,049)$, on the other hand, SNX27 ARC expression was increased $(\mathrm{P}=0.036)$ in HFD fed mice.

Table 1. Summary of SNX3, UBE2O and SNX27 protein expression in the ARC of StD and HFD mice

\begin{tabular}{|c|c|c|c|}
\hline Groups & SNX3 & UBE20 & SNX27 \\
\hline StD & $16.37 \pm 0.39$ & $31.23 \pm 1.31$ & $12.07 \pm 1.00$ \\
\hline StD/HF & $14.80 \pm 0.55$ & $17.011 \pm 0.51$ & $15.52 \pm 0.93$ \\
\hline$p$ & 0.0494 & $<0.0001$ & 0.036 \\
\hline
\end{tabular}

Data are represented as mean \pm standard deviation of arbitrary units (AU) of fluorescence. Statistical significance was calculated Kolmogorov-Smirnov test, followed by Student's T test. 
SNX3, UBE20 and SNX27 Protein Expressions are Altered in the Hypothalamus of High-Fat Diet Fed Mice. Possible Implications for Retrograde Protein Trafficking

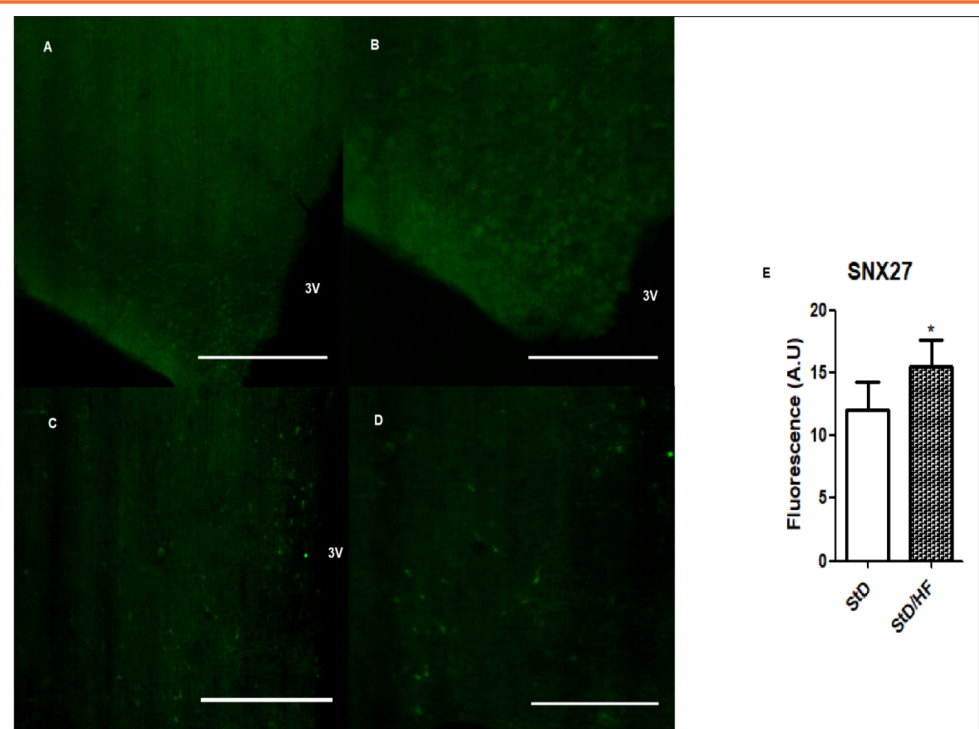

Figure 3. Mice fed with HFD from the $12^{\text {th }}$ week of life until the $20^{\text {th }}$ week of life (HFD) showed increased SNX27 protein expression in the ARC when compared to controls. A and B show representative images of SNX27 immunostaining of StD mice using 10x and 20x objective, respectively. $C$ and D show representative images of SNX27 immunostaining of HFD mice using 10x and $20 x$ objective, respectively. E: Confocal quantification analysis showing an increase in SNX27 immunofluorescence signal in the ARC from HFD mice $(15,52 \pm 0,93 \mathrm{AU})$ when compared to StD mice $(12,07 \pm 1,00 \mathrm{AU})$. ( $(p=0,0367 ; 3 \mathrm{~V}=$ third ventricle; $A U=$ arbitrary unit; Scale bar: $A-C=500$ $\mu \mathrm{m} ; B-D=100 \mu \mathrm{m})$. Data are represented as mean \pm standard deviation of arbitrary units (AU) of fluorescence. Statistical significance was calculated Kolmogorov-Smirnov test, followed by Student's T test.

\section{Discussion}

To our knowledge, this is the first study evaluating the expression of some retromer-WASH components in HFD fed mice. Our main finding is that the expression of SNX3, UBE2O, and SNX27 were significantly altered in HFD obese mice when compared to lean mice. As earlier described, we have shown that HFD induces total corporal weight gain, increased glycemia and plasma leptin levels in C57BL/6 $\mathrm{J}_{\text {Unib }}$ mice (RUBATINO, 2018). Ingle (1949) was the first one to use a palatable diet to induce obesity, followed by Fenton (1953), who induced obesity by administrating a diet containing $50 \%$ of its energy from fat. Moreover. it has been demonstrated that mice fed with HFD for 19 weeks acquired the obesity phenotype with weight gain, hyperglycemia, and plasma leptin increase (GUO, 2009). Considering the time of murine life, HFD exposition at less than 8 week-old of life has its obesity development capacity diminished (NISHIKAWA, 2007). Further more, it has been shown that the peak of murine weight gain is at 9 months or 36 weeks of age (van der HEIJDEN, 2015) and that older mice gain more corporal weight when compared to younger mice (HOUTKOOPER, 2011). Therefore, considering the obese tendency of older mice, we used 12-week old mice to induce weight gain with exposition to HFD and evaluate alterations in the retrograde transport machinery, by measuring the in situ expression of the proteins SNX3, UBE2O, and SNX27 in the ARC of HFD mice. The endosome-to-Golgi retrieval pathway is suggested to form part of the recycling machinery of a variety of proteins and receptors and is essential for diverse cellular functions (SEAMAN, 2004). Thus, we specifically targeted proteins involved in endosomal protein sorting.

Ubiquitylation is a highly conserved process in the cell, being described as essential to actin nucleation and posterior endosomal trafficking (GAUTREAU, 2014; FANG, 2004). The retromer complex (a heterotrimer of VPS35, VPS26 and VPS29) recruits WASH to promote the actin nucleation. Several proteins are involved in retromer-WASH recruitment, including E3-ligase TRIM27, MAGEL2 (melanoma antigen L2), and E2-conjugase UBE2O (GAUTREAU, 2014; SEAMAN, 2013). Indeed, some evidence has shown that RNA interference against UBE2O transcription significantly impairs retrograde transport (HAO, 2013). In the present work, we observed that HFD 
SNX3, UBE20 and SNX27 Protein Expressions are Altered in the Hypothalamus of High-Fat Diet Fed Mice. Possible Implications for Retrograde Protein Trafficking

promotes a very significant reduction in UBE20 expression in the ARC of mice. Other relevant proteins involved in retromer complex interaction with the endosome membrane are the SNX3 and the Rab7 a, these molecules are considered markers of mature endosomes in retrograde transport to TGN (HARRISON, 2014). Moreover, some authors have already shown that SNX3 is also involved in the recycling of the Wnt-binding protein Wntless (HARTERINK, 2011) and of the transferrin receptor (CHEN, 2013). In the present work, we found that SNX3 protein expression was slightly decreased in the ARC of HFD fed mice. Together, these findings led us to hypothesize that endosomal maturation mediated by SNX3 and ubiquitylation via UBE20-conjugase may be altered in the ARC of HFD fed mice. In sequence, we investigate another pathway involved in receptor recycling to the plasma membrane. SNX27 is mainly expressed in neural tissue, being essential to the fast recycling of several receptors from endosomes to the cell surface, such as the N-methyl-d-aspartate (NMDA) (CLAIRFEUILLE, 2016), the GLUT1 (STEINBERG, 2013), the $\beta 2$ (LAUFFER, 2010) and the $\beta 1$ (TEMKIN, 2011) adrenergic receptors. We have observed that SNX27 protein expression was increased in the ARC of HFD fed mice when compared to controls. It was already demonstrated that the SNX27 is essential to life, once SNX27 knockout mice die inside the uterus (CAI, 2011). Moreover, Clairfeuille (2016) have elegantly shown that in vitro phosphorylation of serine residues of SNX27 increases its affinity NMDA receptor. Maybe, such a mechanism could be happening in the ARC of the obese animals, up-regulating the SNX27 expression, and compensating other defective pathways, as the SNX3-mediated retrograde transport. The main limitation of this study was the absence of ObR expression analysis.

We plan to determine ObR expression in the ARC, in addition to other proteins associated with the retrograde and lysosomal routes. To conclude, we found alterations in proteins that are important to endosome sorting of cargo proteins, including the retrograde and the fast intracellular recycling. This work gives us a first view of what is happening in the ARC of obese animals, and what consequences it may imply.

\section{REFERENCES}

[1] Balland E, Cowley MA. New insights in leptin resistance mechanisms in mice. Front Neuroendocrinol. 2015 Oct;39:59-65.

[2] Baver SB, Hope K, Guyot S, Bjørbaek C, Kaczorowski C, Connell KMSO. Leptin Modulates the Intrinsic Excitability of AgRP / NPY Neurons in the Arcuate Nucleus of the Hypothalamus. J Neurosci. 2014;34(16):5486-96.

[3] Belouzard S, Delcroix D, Rouillé Y. Low Levels of Expression of Leptin Receptor at the Cell Surface Result from Constitutive Endocytosis and Intracellular Retention in the Biosynthetic Pathway. J Biol Chem. 2004 Jul 2;279(27):28499-508.

[4] Bouret SG, Bates SH, Chen S, Jr MGM, Simerly RB. Distinct Roles for Specific Leptin Receptor Signals in the Development of Hypothalamic Feeding Circuits. J Neurosci. 2012;32(4):1244-52.

[5] Cai L, Loo LS, Atlashkin V, Hanson BJ, Hong W. Deficiency of Sorting Nexin 27 (SNX27) Leads to Growth Retardation and Elevated Levels of N-Methyl-D-Aspartate Receptor 2C (NR2C). Mol Cell Biol. 2011 Apr 15;31(8):1734-47.

[6] Chen C, Garcia-Santos D, Ishikawa Y, Seguin A, Li L, Fegan KH, et al. Snx3 Regulates Recycling of the Transferrin Receptor and Iron Assimilation. Cell Metab. 2013 Mar;17(3):343-52.

[7] Clairfeuille T, Mas C, Chan ASM, Yang Z, TelloLafoz M, Chandra M, et al. A molecular code for endosomal recycling of phosphorylated cargos by the SNX27-retromer complex. Nat StructMol Biol. 2016 Oct 5;23(10):921-32.

[8] Coll AP, Farooqi IS, O'Rahilly S. The Hormonal Control of Food Intake. Cell. 2007;129(2):251-62.

[9] Cowley M a, Smart JL, Rubinstein M, Cerdán MG, Diano S, Horvath TL, et al. Leptin activates anorexigenic POMC neurons through a neural network in the arcuate nucleus. Nature. 2001;411(6836):480-4.

[10] Cui H, López M, Rahmouni K. The cellular and molecular bases of leptin and ghrelin resistance in obesity. Nat Rev Endocrinol. 2017 Jun 24;13(6):338-51. 
SNX3, UBE20 and SNX27 Protein Expressions are Altered in the Hypothalamus of High-Fat Diet Fed Mice. Possible Implications for Retrograde Protein Trafficking

[11] Derivery E, Helfer E, Henriot V, Gautreau A. Actin polymerization controls the organization of WASH domains at the surface of endosomes. PLoS One. 2012;7(6).

[12] Duleh SN, Welch MD. WASH and the Arp2/3 Complex Regulate Endosome Shape and Trafficking. Cytoskeleton. 2010; 206 (February):193-206.

[13] Elias CF, Aschkenasi C, Lee C, Kelly J, Ahima RS, Bjorbæk C, et al. Leptin Differentially Regulates NPY and POMC Neurons Projecting to the Lateral Hypothalamic Area. Neuron. 1999;23:775-86.

[14] Fang S, Weissman AM. A field guide to ubiquitylation. Cell Mol Life Sci. 2004;61:1546-61.

[15] Fenton PF, Dowling MT. Studies on Obesity. J Nutr. 1953;49(2):319-31.

[16] Gallon M, Cullen PJ. Retromer and sorting nexins in endosomal sorting. BiochemSoc Trans 2015;43(1):33-47.

[17] Gautreau A, Oguievetskaia K, Ungermann C. Function and Regulation of the Endosomal Fusion and Fission Machineries. Cold Spring HarbPerspect Biol. 2014 Mar 1;6(3):a016832a016832.

[18] Guo J, Jou W, Gavrilova O, Hall KD. Persistent DietInduced Obesity in Male C57BL/6 Mice Resulting from Temporary Obesigenic Diets. Sorensen TIA, editor. PLoS One. 2009 Apr 29;4(4):e5370.

[19] Hao Y-H, Doyle JM, Ramanathan S, Gomez TS, Jia $\mathrm{D}, \mathrm{Xu} \mathrm{M}$, et al. Regulation of WASH-Dependent Actin Polymerization and Protein Trafficking by Ubiquitination. Cell. 2013 Feb;152(5):1051-64.

[20] Harrison MS, Hung C-S, Liu T -t., Christiano R, Walther TC, Burd CG. A mechanism for retromer endosomal coat complex assembly with cargo. Proc Natl Acad Sci. 2014 Jan 7;111(1):267-72.

[21] Harterink M, Port F, Lorenowicz MJ, McGough IJ, Silhankova M, Betist MC, et al. A SNX3-dependent retromer pathway mediates retrograde transport of the Wnt sorting receptor Wntless and is required for Wnt secretion. Nat Cell Biol. 2011 Aug 3;13(8):914-23.
[22] Houtkooper RH, Argmann C, Houten SM, Cantó C, Jeninga EH, Andreux PA, et al. The metabolic footprint of aging in mice. Sci Rep. 2011 Dec 31;1(1):134.

[23] IngleD.ASimple Means of Producing Obesity in the Rat. Proc SocExpBiolMedicie. 1940;78(149):3-4.

[24] Kleinert M, Clemmensen C, Hofmann SM, Moore MC, Renner S, Woods SC, et al. Animal models of obesity and diabetes mellitus. Nat Rev Endocrinol. 2018;14(3):140-62.

[25] Lauffer BEL, Melero C, Temkin P, Lei C, Hong W, Kortemme T, et al. SNX27 mediates PDZ-directed sorting from endosomes to the plasma membrane. J Cell Biol. 2010 Aug 23;190(4):565-74.

[26] Münzberg H, Flier JS, Bjørbaek C. Region-specific leptin resistance within thehypothalamus of diet-induced obese mice. Endocrinology (2004) 145:4880-9.

[27] Nishikawa S, Yasoshima A, Doi K, Nakayama $\mathrm{H}$, Uetsuka K. Involviment of sex, strain and age factors in High Fat Diet-Induced Obesity in C57BL6J and BALBcA mice.pdf. Exp Anim. 2007;56:263-72.

[28] Rubatino FVM, Ferreira A, Freitas ML De, Junta $\mathrm{CM}$, Castro CJ De, et al. Alterations in transcript levels of hypothalamic endosomal recycling genes in high-fat diet-fed mice. EndocrinolMetabInt J. 2018;6(6):429-32.

[29] Schwartz MW, Seeley RJ, Woods SC, Weigle DS, Campfield LA, Burn P, et al. Leptin Increases Hypothalamic Pro-opiomelanocortin mRNA Expression in the Rostral Arcuate Nucleus. Diabetes. 1997;46(8):2119-23.

[30] Scott CC, Vacca F, Gruenberg J. Endosome maturation, transport and functions. Semin Cell Dev Biol. 2014;31:2-10.

[31] Seaman MNJ, Gautreau A, Billadeau DD. Retromermediated endosomal protein sorting: all WASHed up! Trends Cell Biol. 2013 Nov;23(11):522-8.

[32] Seaman MNJ, Marcusson EG, Cereghino JL, Emr SD. Endosome to Golgi retrieval of the vacuolar protein sorting receptor, Vps10p, requires the function of the VPS29, VPS30, and VPS35 gene products. J Cell Biol. 1997;137(1):79-92. 
SNX3, UBE20 and SNX27 Protein Expressions are Altered in the Hypothalamus of High-Fat Diet Fed Mice. Possible Implications for Retrograde Protein Trafficking

[33] Seaman MNJ, McCaffery JM, Emr SD. A membrane coat complex essential for endosome-toGolgi retrograde transport in yeast. J Cell Biol. 1998;142(3):665-81.

[34] Seaman MNJ. Cargo-selective endosomal sorting for retrieval to the Golgi requires retromer. J Cell Biol. 2004 Apr 12;165(1):111-22.

[35] Seaman MNJ. Membrane traffic in the secretory pathway. Cell Mol Life Sci. 2008;65(18):2842-58.

[36] Steinberg F, Gallon M, Winfield M, Thomas EC, Bell AJ, Heesom KJ, et al. A global analysis of SNX27retromer assembly and cargo specificity reveals a function in glucose and metal ion transport. Nat Cell Biol. 2013 May 7;15(5):461-71.

[37] Tran DQ, Tse EK, Kim MH, Belsham DD. Dietinduced cellular neuroinflammation in the hypothalamus: Mechanistic insights from investigation of neurons and microglia.Mol Cell Endocrinol. 2016 Dec 15;438:18-26.
[38] Temkin P, Lauffer B, Jäger S, Cimermancic P, Krogan NJ, von Zastrow M. SNX27 mediates retromer tubule entry and endosome-to-plasma membrane trafficking of signalling receptors. Nat Cell Biol. 2011 Jun 22;13(6):715-21.

[39] van der Heijden RA, Bijzet J, Meijers WC, Yakala GK, Kleemann R, Nguyen TQ et al. Obesityinduced chronic inflammation in high fat diet challenged C57BL/6J mice is associated with acceleration of age-dependent renal amyloidosis. Sci Rep. 2015 Dec 13;5(1):16474.

[40] Zhang, Yiying, Proença, Ricardo, Maffei, Margherita, Barone, Marisa, Leopold, Lori, Friedman J. Positional cloning of the mouse obese gene and its human homologue. Nature. 1994. p. 425-32.

Citation: Karla Simone Fernandes, Leonardo Rossi de Oliveira et al. SNX3, UBE2O and SNX27 Protein Expressions are Altered in the Hypothalamus of High-Fat Diet Fed Mice. Possible Implications for Retrograde Protein Trafficking. Archives of Diabetes and Endocrine System. 2019; 2(2): 01-08.

Copyright: (C) 2019 Karla Simone Fernandes, Leonardo Rossi de Oliveira et al. This is an open access article distributed under the Creative Commons Attribution License, which permits unrestricted use, distribution, and reproduction in any medium, provided the original work is properly cited. 